\title{
A transcutaneous carbon dioxide monitor is a useful tool with known caveats
}

To the Editor:

We have read with great interest the article by Mummery et al. [1] on the use of transcutaneous carbon dioxide tension $\left(P_{\mathrm{tcCO}_{2}}\right)$ as a means of measuring carbon dioxide in the acute, unselected medical setting. The authors compared the results of gold standard arterial blood gas analysis sampling with values of $P_{\mathrm{tcCO}}$ measured by Resmed SenTec monitor (SenTec AG, Therwil, Switzerland) in 50 patients admitted to hospital for different diseases, including respiratory problems, non-respiratory sepsis, cardiovascular diseases and other medical diagnoses.

Bland-Altman analysis showed that the bias of the $P_{\mathrm{tcCO}_{2}}$ tended to be $0.16 \mathrm{kPa}(95 \% \mathrm{CI} \pm 1.54 \mathrm{kPa})$ lower than the arterial carbon dioxide tension $\left(P_{\mathrm{aCO}_{2}}\right)$ with $95 \%$ limits of agreement -1.67 to $1.35 \mathrm{kPa}$. Furthermore, the limits of agreement for the two techniques for measuring $P_{\mathrm{tcCO}_{2}}$ was also significantly outside of "what may be an acceptable difference" of $\pm 0.25 \mathrm{kPa}$. Therefore, Mummery et al. [1] concluded that $P_{\mathrm{tcCO}_{2}}$ measured by the Resmed SenTec monitor should not be used in acute clinical settings as an alternative to the $P_{\mathrm{aCO}}$ measured by arterial blood gas analysis sampling. The limitations to the study highlighted that only the Resmed SenTec monitor was tested and that only the forehead position was used to place the sensor.

In a previous real-life study, we have evaluated the accuracy of a similar transcutaneous carbon dioxide sensor (TOSCA; Linde Medical Systems, Basel, Switzerland) for non-invasive estimation of arterial carbon dioxide in 35 severely obese patients affected by different respiratory disorders and admitted to an acute, unselected medical setting [2]. In our study, 18 patients presented arterial $\mathrm{pH}$ less than 7.35 and severe hypercapnia. We showed a general good agreement between $P_{\mathrm{tcCO}_{2}}$ measured by the transcutaneous electrode and $P_{\mathrm{aCO}}$ measured from sampling arterial blood. In our study, the mean difference was of $-0.15 \mathrm{kPa}$, with a standard deviation of the difference of $0.17 \mathrm{kPa}$ and a $95 \%$ limit of agreement of -0.53 to $0.15 \mathrm{kPa}$. We also reported a discrepancy $>0.25 \mathrm{kPa}(>2 \mathrm{mmHg})$ between $P_{\mathrm{tcCO}}$ and $P_{\mathrm{aCO}}$ in 11 of the 55 paired measures, in our study probably due to the heated sensor, which improved the local perfusion [3] but increased the local production of tissue carbon dioxide [4].

Our findings were consistent with those of Mummery et al. [1], showing several samples outside the difference of $\pm 0.25 \mathrm{kPa}$, although using a different electrode and a different measuring site (in our study, the earlobe). Differently from that study, we have considered this difference clinically acceptable in almost all patients, as the differences we have found between $P_{\mathrm{tcCO}}$ and arterial blood gases did not change the clinical outcome in our patients. However, considering as clinically acceptable a maximum difference of $1 \mathrm{kPa}(7.5 \mathrm{mmHg})$, as in other studies [5], we found only three paired measures outside this limit.

Accordingly, $P_{\mathrm{tcCO}_{2}}$ has shown good accuracy when compared to $P_{\mathrm{aCO}_{2}}$ in 25 non-intubated and spontaneously breathing patients with acute respiratory failure admitted to the intensive care unit [6]. $P_{\mathrm{tcCO}_{2}}$ has also been used as a monitoring tool during spontaneous breathing trials in intubated patients, showing a good correlation and agreement between $P_{\mathrm{tcCO}_{2}}$ and $P_{\mathrm{aCO}}$ (bias $-1.5 \mathrm{mmHg}$; lower limit of agreement $-4.4 \mathrm{mmHg}$; upper limit of agreement $7.4 \mathrm{mmHg}$ ) [7]. From these and other studies [8-10], it appears that $P_{\mathrm{tcCO}_{2}}$ overall is relatively accurate and median difference between $P_{\mathrm{tcCO}}$ and $P_{\mathrm{aCO}}$ is relatively low (generally lower than the difference between end-tidal carbon dioxide and $P_{\mathrm{aCO}_{2}}$ ), although large outlier readings even within the same patient are common, can occur at any time and are unpredictable.

@ERSpublications

Although transcutaneous carbon dioxide measurement cannot completely replace conventional blood gas analysis, transcutaneous carbon dioxide sensors could be used in patients with variable levels of hypercapnia also in an acute setting http://bit.ly/2kliEXx

Cite this article as: Maniscalco M, Fuschillo S. A transcutaneous carbon dioxide monitor is a useful tool with known caveats. Eur Respir J 2019; 54: 1900918 [https://doi.org/10.1183/13993003.00918-2019]. 
Although we agree that the measurements of $P_{\mathrm{tcCO}}$ are less informative than arterial blood gases, as isolated elevated $\mathrm{CO}_{2}$ levels give an incomplete picture, in our experience it may be well accepted by patients and staff, as clearly shown also by Mummery et al. [1]. For example, in patients with COPD, we often use measurements of $P_{\mathrm{tcCO}_{2}}$ in conjunction with arterial blood gas measurement. This is done to follow the trends after an initial arterial sample because it provides a continuous measurement and reduces the need for frequent invasive sampling of arterial blood.

In conclusion, we think that although $P_{\mathrm{tcCO}}$ measurement cannot completely replace conventional blood gas analysis, transcutaneous carbon dioxide sensors could be used with caution in patients with variable levels of hypercapnia, also in an acute setting, although in a minority of cases, clinically relevant differences to arterial $P_{\mathrm{aCO}}$ can be observed.

Mauro Maniscalco and Salvatore Fuschillo

Istituti Clinici Scientifici Maugeri IRCCS, Pulmonary Rehabilitation Unit of the Telese Terme Institute, Pavia, Italy.

Correspondence: Mauro Maniscalco, Istituti Clinici Scientifici Maugeri IRCCS, Via Maugeri 4, 27100, Pavia, Italy. E-mail: mauro.maniscalco@icsmaugeri.it

Received: 08 May 2019 | Accepted after revision: 03 July 2019

Conflict of interest: M. Maniscalco has nothing to disclose. S. Fuschillo has nothing to disclose.

\section{References}

1 Mummery V, Rogers E, Padmanaban V, et al. Transcutaneous carbon dioxide measurement is not a reliable alternative to arterial blood gas sampling in the acute medical setting. Eur Respir J 2019; 53: 1801726.

2 Maniscalco M, Zedda A, Faraone S, et al. Evaluation of a transcutaneous carbon dioxide monitor in severe obesity. Intensive Care Med 2008; 34: 1340-1344.

3 Eberhard P, Gisiger PA, Gardaz JP, et al. Combining transcutaneous blood gas measurement and pulse oximetry. Anesth Analg 2002; 94: S76-S80.

4 Griffin J, Terry BE, Burton RK, et al. Comparison of end-tidal and transcutaneous measures of carbon dioxide during general anaesthesia in severely obese adults. Br J Anaesth 2003; 91: 498-501.

5 Bendjelid $\mathrm{K}$, Schutz N, Stotz $\mathrm{M}$, et al. Transcutaneous $\mathrm{PCO}_{2}$ monitoring in critically ill adults: clinical evaluation of a new sensor. Crit Care Med 2005; 33: 2203-2206.

6 Lermuzeaux M, Meric H, Sauneuf B, et al. Superiority of transcutaneous $\mathrm{CO}_{2}$ over end-tidal CO2 measurement for monitoring respiratory failure in nonintubated patients: A pilot study. J Crit Care 2016; 31: 150-156.

7 Henao-Brasseur J, Bedel J, Mutlu G, et al. Transcutaneous $\mathrm{CO}_{2}$ monitoring: a new tool to identify spontaneous breathing trial failure during weaning from mechanical ventilation. A pilot cohort study. Intensive Care Med 2016; 42: $1078-1079$.

8 Spelten O, Fiedler F, Schier R, et al. Transcutaneous $\mathrm{PTCCO}_{2}$ measurement in combination with arterial blood gas analysis provides superior accuracy and reliability in ICU patients. J Clin Monit Comput 2017; 31: $153-158$.

9 Hinkelbein J, Floss F, Denz C, et al. Accuracy and precision of three different methods to determine $\mathrm{PCO}_{2}\left(\mathrm{PaCO}_{2}\right.$ vs. $\mathrm{PetCO}_{2}$ vs. $\mathrm{PtcCO}_{2}$ ) during interhospital ground transport of critically ill and ventilated adults. J Trauma 2008; 65: $10-18$.

10 Lambert LL, Baldwin MB, Gonzalez CV, et al. Accuracy of transcutaneous $\mathrm{CO}_{2}$ values compared with arterial and capillary blood gases. Respir Care 2018; 63: 907-912. 